\title{
JOAQUIM VENÂNCIO FERNANDES (1895-1955)
}

JOAQUIM VENÂNCIO FERNANDES (1895-1955)

Luiz Fernando Ferreira 1

\section{Manguinhos, 1988}

... “José Arcadio Buendia reuniu, no barracão dos fundos, os homens do povoado, e demonstrou a eles, com teorias que acabaram sendo incompreensíveis para todos, a possibilidade de regressar ao ponto de partida viajando sempre para o oriente".

"Cem Anos de Solidão", Gabriel García Márquez

Joaquim Venâncio nasceu na fazenda de Bela Vista (MG), a 23 de maio de 1895. Era a fazenda dos Chagas, da mãe do velho Carlos Chagas. Foram criados juntos. Ligações feudais - no bom sentido - já fortemente estabelecidas. Amizade fraterna, com obrigações recíprocas. Assim também os Borrielos, com Oswaldo Cruz.

Quando terminaram as obras do castelo, Oswaldo ofereceu emprego aos operários do novo Instituto. Trabalho garantido, vida calma. Basílio Aor, o mestre de obras, não aceitou:

- Obrigado, doutor, mas eu não posso ficar. O doutor Luís de Moraes ainda tem muita coisa para construir.

A fidelidade dele era ao arquiteto, não a Oswaldo. Dizem que, quando Basílio morreu, Luís de Moraes não construiu mais. Faltava o homem de confiança.

Em 1916, Joaquim Venâncio veio trabalhar no Instituto Oswaldo Cruz. Naquele tempo, Manguinhos era assim (de um depoimento do Dr.Aragão):

“a área da propriedade era de uns 800 mil metros quadrados, ficando situada entre a Estação de Amorim e o mar. Seu acesso era, na época, sobretudo incômodo por serem escassos os trens, e de difícil navegação o mar raso e lamacento da enseada do Caju que lhe ficava à frente.

Na faixa lamosa, invadida periodicamente pelos mares, que cercava em grande parte o terreno, existiam verdejantes bosques de mangues, entre cujas raízes tentaculares se movimentava incerta uma variada fauna de bizarros caranguejos e em cujas copas altas pousavam alvas garças e pachorrentos socós, cor de cinza, quando não estavam pescando nas águas rasas ou animando o ambiente ermo e tranqüilo desse recôncavo da baía do Rio, com seus vôos brandos e cadenciados... 


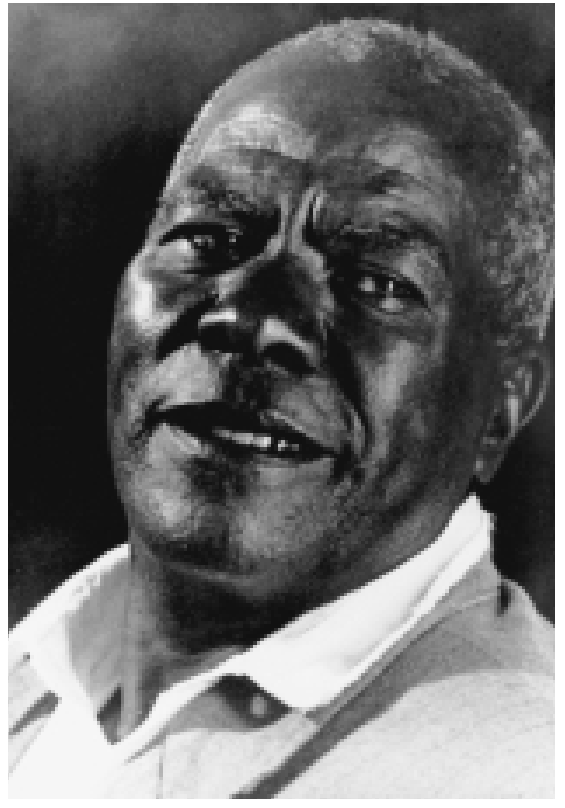

Por todo o terreno, copados tamarineiros, vetustas mangueiras, cajueiros, pitangueiras, goiabeiras, imensos coqueiros, uma majestosa esterculiácea, meia dúzia de casuarinas que foram de especial predileção de Oswaldo".

Tinha a chácara do Amadeu, com legumes, berinjela, alface e fruta de conde.

E se caçava também. De um relato de Olímpio da Fonseca:

“José Vasconcelos fora obrigado a abandonar a serviço ativo, para o qual ficara invalidado, em um acidente de caça, ocorrido nos próprios terrenos do Instituto ao ser acuado por uma matilha de cachorros do mato...

Júlio Magalhães, auxiliar muito tempo de Aristides Marques da Cunha, e que certa vez capturou à mão um jacaré de porte médio e o trouxe vivo às costas para a mesa de necropsia no laboratório".

Era o Manguinhos de Eduardo Marques, meu parente, que aqui fez tese de doutorado em 1907, e cujas histórias povoaram o meu mundo de adolescente. Já escrevi certa vez que foi ele e os Caçadores de Micróbios, de Paul de Kruif, os que mais influenciaram na minha escolha profissional. Foi também o Manguinhos dos colegas de turma de meu pai: Oswaldo Cruz Filho, Gilberto Vilela, Gustavo de Oliveira Castro e José Guilherme Lacorte.

E foi depois o Manguinhos de Lobato Paraense, de Herman Lent, de Hugo Souza Lopes e Sebastião Oliveira, meus professores, com quem tanto aprendi. 
Afinal de contas, era a fazenda de Manguinhos. Lugar bom, tão bom que foi ocupado desde a pré-história. Maria da Conceição Beltrão aqui identificou sambaquis muito antigos e linhas de defesa dos tupinambás. Foi latifúndio dos jesuítas, até que o Marquês de Pombal - já boa mistura de sangue português com sangue negro - expulsou-os das terras de Portugal. Foi fazenda do Amorim, e depois foi da municipalidade, que aqui construiu um forno de cremar lixo, e que, de acordo com longa tradição, nunca chegou a funcionar.

Dizem os arqueólogos que os bons espaços são ocupados sucessivamente. E Manguinhos é um bom espaço. Continua a ser, apesar de tudo. Apesar até da Avenida Brasil.

Joaquim Venâncio veio trabalhar em Manguinhos e deu certo. O Dr. Lutz teria dito certa vez: "Não troco o Venâncio por nenhum doutor de Oxford ou de Cambridge". Se não disse, pensou. Eficiência nos processos de seleção de pessoal? Competência do Serviço de Recursos Humanos? Evidentemente que não. Não havia nada disso nessa época. As coisas eram muito mais simples e davam certo.

Venâncio veio porque era amigo do velho Chagas, o diretor, tinham sido amigos de infância na fazenda. Mais tarde, viria o Venancinho, porque era sobrinho do Venâncio. E começou cuidando das vacas que pertenciam ao tio. Tudo aqui dentro; vendiam o leite. Hoje é, sem dúvida, um dos melhores técnicos de laboratório em atividade.

Isso me lembra Marilene, que trabalhou comigo até há pouco tempo. Um dia, a Nilséia ofereceu a ela o dobro do salário. Perguntou à mãe, a nossa Madalena, que até hoje trabalha para minha mãe.

- Só se doutor Luiz Fernando deixar - respondeu. Eu deixei. A avó era afilhada de casamento de meu pai. Casamento na fazenda. A noiva de vestido branco, longo, de véu e grinalda, montada a cavalo. Tudo isso debaixo de uma chuva torrencial. E com baile até amanhecer o dia.

Muitos vieram meninos ainda. O Ambleto com 10 anos. $\mathrm{O}$ pai foi o mestre de obras durante a construção do castelo. O irmão trabalhava na encadernação. Atíllo Borrielo veio com 15 anos. Aqui já trabalhavam dois irmãos: Antonio e Benedito. Depois viriam mais dois. Gente de São Luiz do Paraitinga. Gente boa, ligada ao Dr. Bento Gonçalves Cruz.

E havia também "outras formas de seleção". A seca na Bahia levou Abíllo Lopes de Oliveira para Botucatu. Bom lavrador. Lá contraiu leishmaniose. Veio para o Rio de Janeiro se tratar na Santa Casa da Misericórdia. Para poder acompanhar melhor o tratamento, Gaspar Vianna o leva para Manguinhos.

Para justificar casa e comida, começa a dar uma ajudazinha aqui, outra ali. Aprende a ajudar nas autópsias. Aprende técnica histológica. Entrou como doente, aposentou-se como técnico de laboratório. Excelente funcionário. 
Ilo Miranda Bastos foi meu auxiliar durante muitos anos no velho Pavilhão Carlos Chagas, no Hospital São Francisco de Assis, em plena zona do baixo meretrício. Tinha uma úlcera angiodérmica e esquistossomose. Ofereceu trabalho em troca de tratamento, casa e comida. Foi auxiliar indispensável na minha tese de doutorado. Hoje é médico pediatra, e dos bons.

No depoimento do Atílio Borrielo ao grupo de história oral da Casa de Oswaldo Cruz: "Esse Raymundo Onório tem uma história interessante. Porque Oswaldo Cruz o apanhou, garotinho, no Amazonas. Tipo meio bugre, meio índio, e trouxe para o Rio de Janeiro e educou". Foi dos melhores em desenho técnico no Brasil. Cursou a Escola de Belas Artes, foi professor de desenho científico.

Francisco Gomes, o nosso Chico Trombone, veio com 7 anos. Estava magrinho, e o tio, que trabalhava com Carlos Chagas, decidiu levá-lo para Lassance. Novos ares lhe fariam bem.

Chagas mandou levarem o menino de volta, pois aquela era uma área endêmica e o garoto não podia ficar. Mas só havia trem dali a uma semana.

Naquela noite, um gambá na árvore ao lado não deixou o menino dormir. Pela manhã, Chico resolveu subir na árvore para capturá-lo. Quando Chagas voltou do trabalho de campo, encontra o garoto no alto da árvore, lutando com o bicho:

- Não deixa ele fugir, menino. Não deixa fugir. Eu quero examiná-lo.

Chico desce da árvore vitorioso e entrega o gambá ao Dr. Chagas.

Examinaram o sangue do animal, tendo encontrado Tripanosoma cruzi.

Um novo reservatório. Descoberta importante. Ficaram amigos.

Do Rio de Janeiro vêm cartilhas, tabuadas e livros de primeiras letras.

- O menino fica, diz Chagas. Eu mesmo vou ensinar a ele ler, escrever e fazer conta - E ensinou. Começou assim.

O Zé Cunha veio com 13 anos. Ficava de joelhos na cadeira para poder olhar no microscópio.

Eram meninos pobres, aprenderam no trabalho, foram selecionados pelo coração. Eram competentes. Era assim e dava certo. E, às vezes, ainda dá.

Em Paleoparasitologia, além dos meus dois doutores, Adauto e Ulisses, só confio no diagnóstico do Benjamin.

Benjamin Martins Ribeiro Filho. Só completou o curso primário. Começou como meu chofer. Cada dia voltávamos para casa por um caminho diferente: "Todo dia igual é muito chato, doutor. É preciso inventar coisa nova". Em certo período, a Fundação dava uma cota de gasolina e o chofer. O carro não. Eu tinha um fusquinha caindo aos pedaços. Benjamin usava o uniforme completo: terno azul-marinho, gravata preta, sapato de verniz e quepe. Certa vez, durante uma reunião na UERJ, Fernando Beviláqua me pediu:

- Você pode mandar levar o prof. Fulano ao aeroporto? Tratava-se de ilustre catedrático, paulista quatrocentão, família tradicional. 
Na volta, o Benjamin me contou:

- Quando ele me viu assim de uniforme, gostou. Mas quando ele viu o carro, fez uma cara, que eu pensei que ele não ia entrar.

As viagens a Sumidouro democratizaram as nossas relações. Ficamos amigos. Nos atoleiros eu descia para empurrar, ele ficava no volante:

- Se o senhor for guiar, doutor Luiz Fernando, nós vamos atolar e nunca mais saímos daqui.

Veio para o laboratório. Gostou. Aprendeu. É dessa gente que pensa, e pensa bem. Hoje é meu irmão. Só terminou o curso primário. Mas assinou comigo, com Adauto e com Ulisses vários artigos no Paleopathology Newsletter.

Quando Joaquim Venâncio faleceu, em 27 de agosto de 1955, teve seu necrológio publicado na Revista Brasileira de Biologia. Lugar de necrológio de cientista famoso. De gente de Universidade, de Academia de Ciências.

Cito textual:

“Joaquim Venâncio conseguiu, durante cerca de 35 anos em que trabalhou ativamente, aprender zoologia, que conhecia de modo invejável. Como decorrência das contingências da vida, não teve oportunidade de instruir-se, mas sua mentalidade era de um homem culto. Pela convivência com o doutor Lutz e com outros zoólogos, pela observação direta do que via nas excursões no laboratório, adquiriu conhecimento detalhado de vários grupos zoológicos, principalmente anfíbios, moluscos fluviais e trematodeos. Chegou a conhecer muito bem os anfíbios e, com grande facilidade, os distinguia, nas excursões, pela voz...

...Dadas as indicações feitas pelo Dr. Lutz em seus trabalhos, há casos em que foi citado na literatura como colaborador direto."

Entrou no laboratório como servente, para limpar o chão. Um dia, o Dr. Lutz chamou a Berta e disse:

- Precisamente você deve ensinar algumas técnicas a este jovem. Ele é inteligente. Vai longe.

Do discurso do Dr. Lobato Paraense, quando inauguramos o Politécnico:

“Durante os estudos feitos pela herpetóloga Doris Cochran, do Museu Nacional dos Estados Unidos, em 1935, e dos quais resultou importante monografia sobre as rãs do Sudeste do Brasil, Joaquim Venâncio acompanhou-a por Belo Horizonte, Lassance, Pirapora, Ouro Preto, São Paulo, Alto da Serra e Santos.

Tão impressionada ficou aquela pesquisadora com sua competência, que tudo fez para levá-lo para sua instituição.

Um dia perguntei-lhe se não tinha tido vontade de trabalhar nos Estados Unidos. Respondeu-me que sabia que lá iria ganhar muito mais, porém que preferia ser um negro com dignidade no Brasil. 
Joaquim Venâncio era, sem dúvida, um naturalista. Era competente: tinha o domínio do ofício, a maestria da arte."

Certa feita, o Museu de Berlim necessitava de, pelo menos, dois exemplares, um macho e uma fêmea, de uma espécie rara de perereca da América do Sul.

Diante de tão árdua tarefa, o embaixador alemão, depois de várias semanas de dificuldades, procura o Diretor do Instituto Oswaldo Cruz. Expõe o seu problema e pede ajuda.

- O Venâncio pode ajudá-lo - diz o Dr. Aragão, e manda chamá-lo.

- O senhor quer hoje mesmo ou pode ser amanhã? O Dr. Lutz me mandou corar umas lâminas e eu ainda não acabei - responde Venâncio, ao ser inteirado do problema.

Incrédulo, o embaixador se despede. Como podia ser tão difícil para ele o que parecia tão fácil para aquele negro?

No dia seguinte, pela manhã, Venâncio se apresenta na embaixada levando 30 exemplares, exatamente 15 machos e 15 fêmeas, todos devidamente fixados, conservados, etiquetados e corretamente classificados.

Aprendi, nos meus tempos de estudante na Faculdade de Medicina da Praia Vermelha, a fazer a reação da Galli-Manini para diagnóstico de gravidez. Injeta-se a urina da mulher no sapo. Se estiver grávida, os hormônios existentes vão estimular a produção de espermatozóides pelo sapo.

Certa vez, o Chico Trombone me contou: "Joaquim Venâncio estava examinando sapos para o Dr. Lutz, examinando protozoários da cloaca. Aí chegou uma moça trazendo urina para exame. Venâncio mandou ela sentar ao lado dele e esperar um pouco. Como ela não gostava de sapo, ficou jogando urina nos bichos. Quando Venâncio foi examinar os sapos, encontrou uma grande quantidade de espermatozóides. Fato curioso, que ele mostrou ao Manini, que então visitava o Instituto. Quando Dr. Lutz voltou de viagem, contou-lhe o caso.

- Precisamente não se deve mostrar nada a ninguém, enquanto não estiver publicado - respondeu Lutz.

E o Chico termina a história, dizendo: "Não deu outra, doutor, os gringos publicaram".

“Era a escola do Venâncio, né. Foi muito boa... mas não pra ganhar dinheiro, né"...

(Venâncio Bonfim)

Formou escola, ensinou, e mais de uma vez ouvi: "lsso eu sei fazer, doutor, aprendi com o Joaquim Venâncio". Gostava de colaborar, de ajudar a todos. Era pessoa estimada. Todo mundo gostava dele.

E a escola era risonha e franca. O que vinha da Europa ganhava sabor local. Tropical. Adaptava-se, como o português. Se não fosse assim, não tería- 


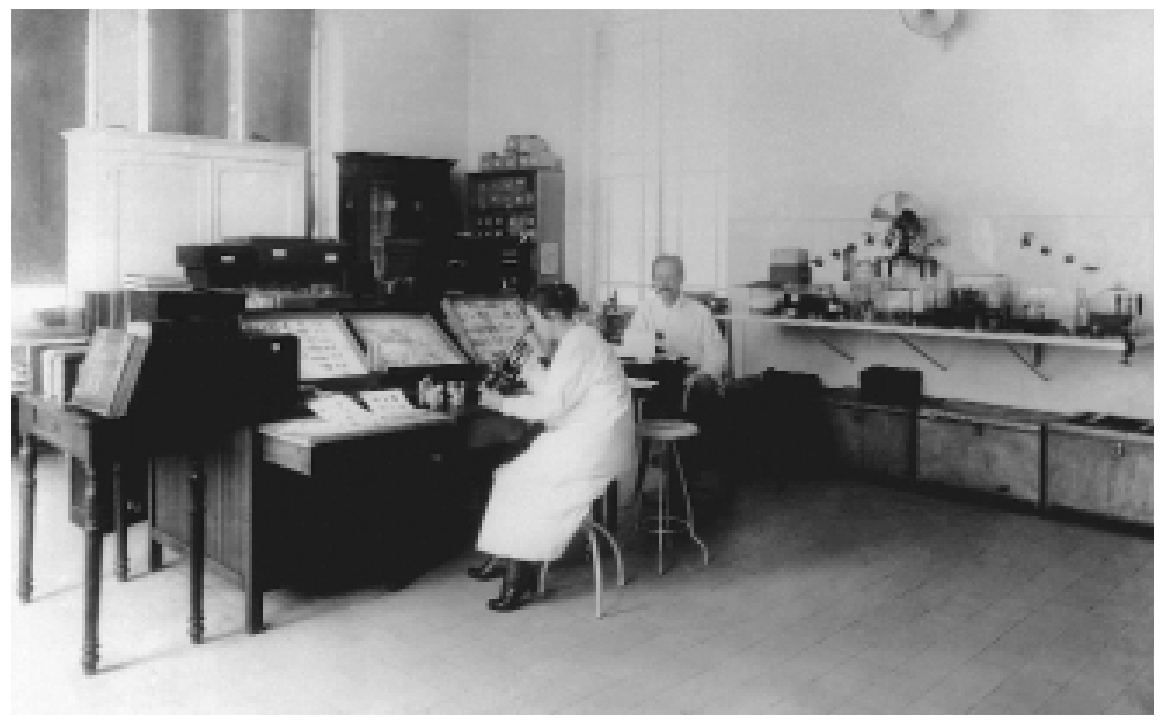

Dr. Adolpho Lutz, e sua filha, Bertha Lutz, em seu laboratório em Manguinhos.

mos o nosso Instituto Pasteur do lado de baixo do Equador. Era escola séria. Mas tinha o seu lado lúdico, gostoso. Religioso, mas sem voto de castidade. Ainda do Dr. Lobato:

“De tempos em tempos, circulavam rumores sobre certos sucessos creditados a conta do charme do Venâncio... a maioria divertia-se com esses comentários e, tácita ou abertamente, aprovava o herói da história. Alguns mais radicais diziam que Venâncio era o que a gíria de hoje chama de paquera. Prefiro simplesmente acreditar que, em circunstâncias favoráveis, ele simplesmente não dormia no ponto".

Afinal de contas, os doutores não eram diferentes.

Contou-me Sebastião de Oliveira que, de certa feita, apareceu pelo Instituto uma húngara que, além de cientista, era uma mulher e tanto. Grande, sensual, diferente.

No dia seguinte, sábio ilustre que aqui fazia pesquisas em Parasitologia, e que eu tive o prazer de conhecer, convidou-a para jantar.

Joaquim Venâncio a Sebastião:

- Não podia deixar de ser, doutor. É a tradição da casa.

Os cientistas e os auxiliares confraternizavam nos gostos semelhantes. Tudo na boa tradição portuguesa, desde Pedro I.

Fazia-se a vacina da manqueira, descrevia-se o ciclo do Hoemoproteus columbae, o curso de aplicação, Política de Saúde, Epidemiologia, com competência, com seriedade. 
E divertia-se também.

Quando o Serviço de Saúde Pública deixou de usar tração animal em seus veículos, ofereceu a tropa de mulas ao Instituto. Era preciso ir buscá-las em General Severiano. E a turma foi. Na saída, encontraram na cocheira uma quantidade de casacas e cartolas. Estava feita a festa.

Atravessaram a cidade tocando a tropa de mulas, vestindo cartola e casaca, sem camisa e sem sapatos. Todo mundo parava para olhar. Eles se divertiram. O Malho, revista da época, fotografa e aproveita para espicaçar Carlos Chagas, o diretor.

Chagas repreende, com um pouco de irritação e um pouco de carinho. E tudo terminou bem. Foi divertido.

A Escola dava casa e comida. Alojamento organizado para os auxiliares? Nada disso. Tudo muito mais simples. Falava-se com o administrador e depois ia-se ao hospital apanhar um colchão, lençol, travesseiro e toalha de banho. Escolhia-se um bom lugar, o pombal, um canto da cocheira, ou de algum outro pavilhão vazio. E ali se morava.

Comida de graça; café, almoço, lanche e jantar. Os que estudavam fora, à noite "assaltavam" a despensa na volta. Era justo. A Escola era risonha e franca e com autoritarismo da época, sem dúvida. Mas com revide à altura, com gozações espirituosas, que, bem ou mal, eram digeridas.

Certa vez, Atilio encontra com Olimpio da Fonseca, então diretor de Manguinhos e Catedrático da Faculdade de Medicina, na escadaria do castelo:

- Atilio, eu estou precisando de uma amostra de T. equinum lá para a Faculdade de Medicina.

Resposta: - Tá ruim, doutor, acho que perdemos a cepa.

Olimpio retruca: - Lá na Faculdade, nós somos poucos e com condições de trabalho muito piores e nunca perdemos uma cepa. Isso não pode acontecer.

Algum tempo depois, chega o Américo, servente da Faculdade, com uma carta do assistente do Olimpio para o Atilio:

- Prezado Borrielo, perdemos várias cepas aqui na Faculdade e venho te pedir a gentileza...

Atilio responde:- Américo, eu tenho tudo que ele quer e vou te dar. Mas antes pede ao Dr. Olimpio para dar um visto nessa carta autorizando.

Américo volta: - Ele leu, ficou uma fúria e rasgou, não sei por quê.

Atilio: - Vai ver que tinha alguma coisa de errada, né?

O Teophilo Martins era exímio em criação de barbeiros. Costumava dizer: "Fiz a biologia do bicho, o Dr. Neiva publicou".

Afinal de contas, trópico é trópico. Impossível a reprodução fiel dos modelos do Norte.

Aqui, Hamlet William vira Ambleto, sem perder a competência. $\mathrm{O}$ auxiliar do doutor Costa Cruz era analfabeto total. Só comprava jornal quando ti- 
nha fotografia para ver. Mas não errava um repique, uma semeadura ou uma inoculação. Era capaz nas técnicas mais modernas. Podia-se confiar nele.

E não eram especializados. Faziam de tudo. O pessoal da Rockfeler, quando chegou aqui, ficou admirado.

E amavam essa casa, tinham orgulho dela. Manguinhos foi mito desde o seu nascimento, o castelo da eterna sabedoria, no alto da colina sagrada.

Joaquim Venâncio morava aqui em Manguinhos. Tinha uma casa, onde vivia com a mulher, D. Sebastiana Batista de Carvalho Fernandes, e os cinco filhos: Celso, Joaquim, Renée, Wanderley e Hugo. Três trabalharam no Instituto. Venâncio tinha sua horta, suas galinhas, suas vacas. Aqui trabalhava. Aqui era, portanto, a sua casa.

A partir de certa época, sua vida se entrelaça de tal maneira com a de Adolpho Lutz que é impossível falar de um sem falar do outro. Figura admirável, de conhecimentos amplos, um erudito, no bom sentido, Lutz tinha muito do cientista ranzinza. Era uma forma de exprimir a sua liberdade de pensar e de agir. Livre, não se curvava às convenções tradicionais. E nunca deixava de usar "precisamente" no início de suas frases.

Certa vez, o Diretor do Instituto, acompanhando figura ilustre da política nacional, entra no laboratório do Dr. Lutz, que está ao microscópio, e com certa timidez, pede que mostre o laboratório ao visitante. Lutz, sem levantar o olhar do microscópio, responde:

- Precisamente o Venâncio vai mostrar, porque eu estou muito ocupado.

Certa vez, o Dr. Lutz adoeceu e J. Pinto, o grande fotógrafo de Manguinhos, foi visitá-lo. Entra, pergunta como está o doente. Lutz responde, descrevendo sumariamente os sintomas e informando que já está melhor.

Pergunta então pela família do fotógrafo, que responde que vão todos bem. Lutz, então, levanta-se, entrega o chapéu ao visitante e diz:

- Precisamente, Pinto, você agora vai embora, porque já dissemos tudo que havia para ser dito e eu agora quero descansar um pouco.

$\mathrm{O}$ aspecto austero, óculos de aro de ouro na ponta do nariz, os grandes bigodes maltratados, terno preto e chapéu coco que as fotografias nos mostram não escondiam o seu senso de humor.

Certa vez, foi ao seu laboratório um sábio germânico, ilustre, pretensioso e arrogante. Lutz começa a fazer-lhe uma série de perguntas em alemão. Uma atrás da outra. Tendo dificuldade em responder, e meio desconcertado, o pesquisador retruca:

- Dr. Lutz, o senhor está me passando uma sabatina.

Ao que ele responde:

- E precisamente o senhor está se saindo muito mal.

Quando estava cansado, durante as excursões, gostava de deitar-se embaixo de uma árvore e declamava em voz alta e no original Homero ou Horacio. Era repousante. 
Apesar disso, às vezes, era literalmente um gozador. Contava Oliveira Castro que, certa vez, viajava com Lutz pelo interior um grupo de jovens cientistas. Cansados, param em uma clareira para descansar. Lutz abre um embrulho de jornal, de onde retira bananas e começa a comer.

- Os senhores gostam de bananas? - pergunta.

Famintos, todos respondem:

- Gostamos, sim.

- Pois precisamente da próxima vez, tragam bananas. Essas são para mim e para o Venâncio.

A amizade que uniu esses dois homens, o espírito de colaboração entre eles, o que resultou do trabalho comum, é uma parte significativa da história de Manguinhos.

Quando o Dr. Lutz ficou muito velho e doente, nem assim parou de trabalhar. Quando precisava sair do laboratório para fazer capturas de animais nos mangues daqui, o robusto Venâncio o carregava nas costas. Isso poderia parecer prepotência às gerações de hoje.

Mas compreende-se melhor se essa história for contada junto com outra, passada poucos anos antes.

Foi quando o rei Alberto veio ao Brasil. Fez-se uma comitiva de sábios para acompanhar a rainha - naturalista amadora - em passeio a cavalo pelas florestas da redondeza. O Dr. Lutz, muito contrafeito, é incluído no grupo. E, como não poderia deixar de ser, o Venâncio vai junto. As mulheres, nesse tempo, montavam de lado na sela.

A primeira dificuldade que surge é quando uma das damas da rainha, querendo ser gentil, aproxima o seu cavalo ao do sábio caturra e procura puxar conversa. Sem ouvir o que lhe foi perguntado, Lutz pontifica, dirigindose à jovem:

- Precisamente os homens é que deveriam montar de lado, porque as mulheres não têm certos órgãos, que ficam amassados contra a sela.

Mas isso não foi o mais importante. O mais importante foi que, quando chegou a hora do almoço, prepararam-se duas mesas para o piquenique; uma para a rainha, as damas e as demais pessoas de estirpe; outra para os criados.

Enfurecido, Lutz protesta:

- Precisamente, ou me sento eu e o Venâncio na mesa de cá, ou eu e o Venâncio na mesa de lá.

E Manguinhos foi se modernizando. Um dia apareceram as mulheres para trabalhar aqui. O primeiro problema foi em relação aos banheiros. Não havia banheiro para mulheres. Isso Oswaldo não previu. Enfim, fazem-se arranjos, mais ou menos precários, que no castelo subsistem até hoje, exceto no último andar.

Até onde sei, as primeiras são modestas funcionárias administrativas. Ainda não competem. Mas o movimento feminista é forte. E para cá vem um 
dos seus maiores expoentes, Bertha Lutz. Ainda os Lutz. Na faculdade de Medicina, fui aluno de Gualter Lutz, filho do Dr. Lutz, irmão da Bertha. Homem de fino trato, elegante, tímido mesmo, eu diria.

Além do reconhecido domínio nos assuntos de sua cátedra-Medicina Legal - era poliglota, tinha prêmios como violonista e, me contou o professor Paulo Lacaz que, ao falecer, estava trabalhando em uma nova tradução da Ilíada, porque as existentes, segundo ele, deixavam ainda muito a desejar.

A agressividade, portanto, ficou com a Bertha. Além de cientista, com contribuições fundamentais ao estudo dos anfíbios anuros, foi líder feminista. Política expressiva, figura entre as primeiras mulheres a se elegerem deputadas no Brasil. Participava de tudo. Sem perder a ranhetice. Contou-me Eduardo Correa Lima que, certa vez, durante um congresso no Museu Nacional, se dirigiu a Bertha. Queria conhecê-la, pois a admirava muito.

- Eu não o conheço e agora estou muito ocupada. Não tenho tempo para o senhor. - E o deixou falando sozinho.

Mas era uma lutadora. Estava sempre à frente quando se tratava das coisas novas, em ciência ou em política.

Mais uma vez, a palavra abalizada de Lobato Paraense:

“Uma questão me intrigava desde a infância. Acostumado desde cedo a ler jornais, muito me impressionou a notícia publicada, mais ou menos em 1928, da Lei que concedia o direito de voto às mulheres no Rio Grande do Norte proposta pelo governador Juvenal Lamartine e aprovada pelo governo daquele estado.

Quando, depois de 1930, o voto feminino foi instituído no Brasil, mais ainda me ardia a curiosidade: qual a razão do pioneirismo do Rio Grande do Norte, e não do Rio de Janeiro ou de São Paulo?

Conversava um dia com Venâncio, que devotava grande afeição a Bertha... contou-me ele que um dos maiores amigos dela tinha sido o governador Lamartine."

Dos anos de trabalho de Venâncio com Bertha, contam-se uma série de histórias.

Certa vez, estavam fazendo captura de sapos na floresta da Tijuca. Nessa época, a polícia estava em campanha contra os namorados que se refugiavam na floresta.

Os dois são levados para a delegacia. O delegado é sarcástico:

- A senhora, uma moça educada, e ainda por cima com um negro?

Indignada, Bertha pega o telefone:

- Eu vou chamar o João.

Riem - Pode chamar.

Bertha ao telefone:

- João, eu estou na delegacia tal. Venha para cá imediatamente. 
Troças, que terminaram logo que entra o João. Era o João Alberto, o chefe de Polícia.

Mas o que importa são os trabalhos científicos em que Venâncio colaborou.

E a escola que se formou. Uma escola de técnicos competentes e dedicados. E feita com afeto, com amizade, com o coração, enfim. E com as tripas também. É a ajuda inestimável do auxiliar técnico, sem a qual é impossível fazer ciência.

Assim eram aqueles tempos. Assim era aquela gente. Assim era o Venâncio.

É bom conhecer um pouco da história deles. A gente aprende muito.

Joaquim Venâncio Fernandes foi escolhido para patrono do nosso Politécnico, não gratuitamente, não por questão de moda, de charme, de querer agradar. Mas porque ele foi, realmente, a síntese, feitos os ajustes da época, do que nós pretendemos ao criar um centro de formação de pessoal em nível auxiliar.

\section{Nota}

1 Pesquisador do Departamento de Endemias Samuel Pessoa, Escola Nacional de Saúde Pública, Fundação Oswaldo Cruz, Rio de Janeiro, RJ. <ludovico@manguinhos.ensp. fiocruz.br $>$ 